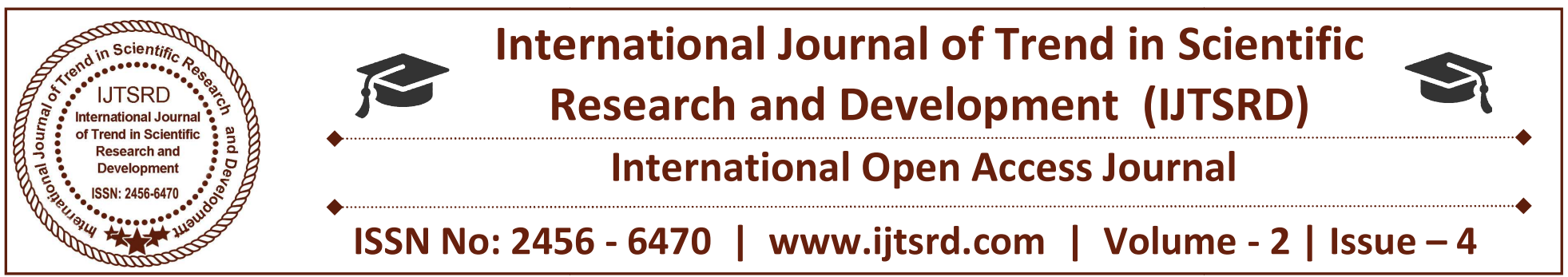

\title{
The Comparative Study on Improvement of Tender Systems in Myanmar
}

\author{
Htun Myint, Htet Thinzar Thein \\ Department of Civil Engineering, Yangon Technological University, \\ Republic of the Union of Myanmar, Yangon, Myanmar
}

\begin{abstract}
The purpose of this paper is to improve the different types of only public tender systems and contract systems in Myanmar. The study is divided into two parts. The first one is comparing the tender systems and the second is comparing the contract systems. Firstly, tender systems of each ministry are studied. When studying the existing practices of tender systems in Myanmar, there are many deficiencies in each ministry and they are unsystematic. To improve the tender system that is different and has defects, tender systems of each ministry are compared. A better and suitable tender system is defined from comparing each ministry. Then that better and suitable tender system is compared with American Institute of Architect (AIA). The suitable facts for Myanmar and the key factors or components that should involve are taken into account. And then the improved tender system that is more suitable and perfect gets. Secondly, contract systems of each ministry are studied. The bid phase has defects for making contract after awarding the tender. There are many problems in current existing contract bid because of weakness and difference of bid phase. To solve them, an improved contract system that should include the suitable facts for each contract investigate and constructs for Myanmar.
\end{abstract}

Keywords: Public tender, Tender system, Contract system, American Institute of Architect, Deficiencies

\section{INTRODUCTION}

Tendering is the process by which bids are invited from interested contractors to carry out specific packages of construction work. It should adopt and observe the key values of fairness, clarity, simplicity. The tendering process is generally utilized for procurements or contracts involving substantial amounts of money. Tendering is utilized by:

1. Government departments, offices and agencies

2. Private sector companies and businesses

3. Non-Government Organizations

4. Overseas markets and businesses

Tenders are generally widely advertised to offer opportunities to a number of suppliers, encourage competition and provide a greater pool of offers to select interested suppliers will prepare a tender, the documents that outline the offer that they are making, and will include pricing, schedules. They will outline their advantage over competitors, provide information on qualifications, competencies and experience. Further they have to demonstrate how their bid offers the best value for money. The offer that meets the best for all of the requirements outlined in the request and provides value for money should win the contract. To perform this study, nine ministries are selected for tender and eight ministries are selected for contract.

\section{LITERATURE REVIEW}

The aims of selection are to find a contractor who can supply a product for a competitive price, and can demonstrate the following:

1. A reputation for good quality workmanship and efficient organization.

2. The ability to complete on time.

3. A strong financial standing with a good business record.

4. The expertise suited to the size and type of project. 
5. An understanding of the requirements of the scheme in terms of the type of work, the quality expected and the need to achieve target completion dates.

The estimating team will consider construction methods and employ planning techniques to:

1. Highlight any critical or unusual activities.

2. Examine alternative ways of tackling the work.

3. Calculate optimum durations for temporary works and plant.

4. Reconcile the lab or costs in the estimate with a programme showing resources.

5. Determine the general items and facilities priced in the preliminaries section of the bill.

6. Check whether the time for completion is acceptable.

Four parts of tender systems are described.

\section{DOCUMENTS USED AS A BASIS OF A TENDER}

The basis of the tender will dictate the way in which the contractor will be paid and the relative accuracy of the estimate. The contractor's bid will be for one of the following:

1. Fixed price contract: where the sum of money is stated in the contract as payment for work, the payment may be adjusted according to strict conditions in the contract.

2. Measurement contract: will allow the contract sum to be calculated later, usually as the aggregate of various rates submitted by the contractor. The contract sometimes includes a target price.

3. Cost-reimbursement contract: an arrangement whereby the cost, whatever it may be, will be paid by the client on the basis.

\section{COMPETITION AND NEGOTATION}

The following points illustrate the coverage of the Codes:

1. Preliminary enquiry - contractors are given the opportunity to decide whether they wish to tender by receiving a preliminary enquiry letter.

2. Number of tenderers - the recommended number of tenderers is a maximum of six and further names could be held in reserve.

3. Tender documents - the aim of the documents is that all tenders will be received on the same basis so that competition is limited to price only.

4. Time for tendering - normally at least four working weeks should be allowed, and more time may be needed depending on the size and complexity of the project.

5. Qualified tenders - tenderers should not try to vary the basis of their tenders using qualifications. Queries or unacceptable contract conditions should be raised at least 10 days before tenders are due. The consultants can then tell all the tenderers of their decisions and if necessary extend the time for tendering.

6. Withdrawal of tenders - a tender may be accepted as long as it remains open, a definite period is usually stated in the tender documents. The tenderer may withdraw his offer before its acceptance.

7. Assessing tenders - the tenders should be opened as soon as possible after they are received.

8. Examination and adjustment of priced bills - the PQS will treat the information in the tender documents as confidential and report errors in computation to the architect and client.

9. Negotiated reduction of tender - the code of procedure recognizes the need to look for savings in the cost of a project.

\section{ABUSE OF TENDER PROCEDURE}

1. Large tender lists

2. Short tender periods

3. Tender documentation

4. Asking for tenders when the work is unlikely to proceed

5. Qualified tenders and alternative bids

6. Failure to notify results

7. Late receipt of tender documents

\section{DECISION TO TENDER}

The decision to tender should be made by the chief estimator or general manager using the following points:

1. Is the work of a type which the contractor has experience, both in winning tenders and completing profitably? Does it conflict with the company's objectives?

and future workload?

2. How many contractors will be invited to tender?

3. Has the contractor the necessary supervisory staff and labor available, he may not wish to recruit untried and unknown personnel in key positions?

4. Will the estimating department have staff available with suitable expertise for the type of work to be priced?

5. Does the location of the proposed site fit the organization's economic area of operation? 
6. Are there too many risks in the technical and contractual aspects of the project?

7. Will suitable documents be produced for tender purposes? A busy estimating office may give priority to work that has been measured. Poor documentation might give a clue to the standard of working documents during construction.

8. Has enough time been given to prepare a sensible estimate?

9. What will be the cost of preparing the tender? A contractor might limit the number of design and construct tenders. In the majority of cases, these costs are not recoverable.

\section{METHODOLOGY}

In this study, different types of tender systems for four ministries are selected. The first is taking questionnaires and personal interviews to the government agencies for tenders.

Tender systems of each department in one ministry are studied and compared. When comparing each department, there has deficiencies and differences in each department. The required facts are added to the needed department. Then, tender systems of each ministry are compared.

\section{RESULTS FROM STUDY}

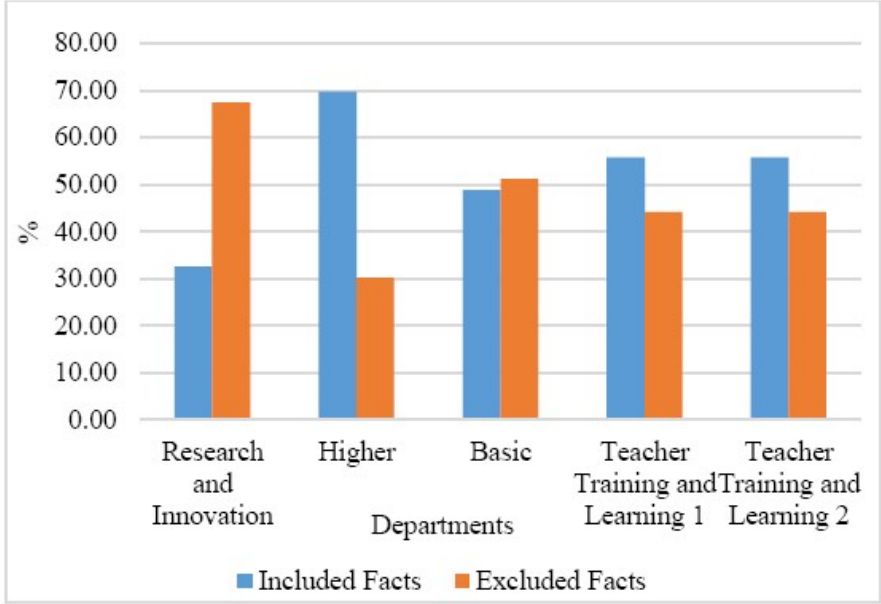

Figure8.1. Comparison of the same and different facts of each department for ministry of education

The departments for ministry of education are research and innovation, higher education, basic education, teacher training and learning. The same facts of each department are approximately $12 \%$ and the different facts for each department are approximately $89 \%$. The same facts are lower about $77 \%$ than the different facts. The department of higher education is highest with $70 \%$ and that of research and innovation is lowest with $33 \%$ for the included facts. The department of research and innovation is highest with $67 \%$ and the department of higher eduation is lowest with $30 \%$ for the excluded facts. The remaining departments are not different too much. The remaining departments are $49 \%, 56 \%$ and $56 \%$.

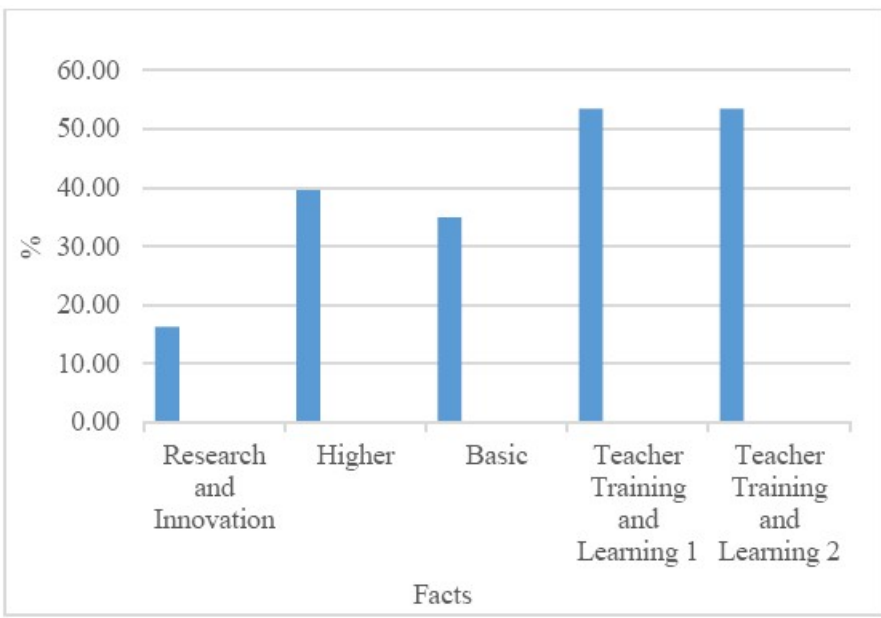

Figure8.2. Comparison of the same facts (coincide) of each department for ministry of education

For same facts (coincide), the highest is the department of teacher training and learning 1 and 2 with $54 \%$ and the lowest is the department of research and innovation with $16 \%$. The deficiency is $37 \%$ and little high. The higher and basic education are $40 \%$ and $35 \%$. The deficiency is $5 \%$ and it is not too high.

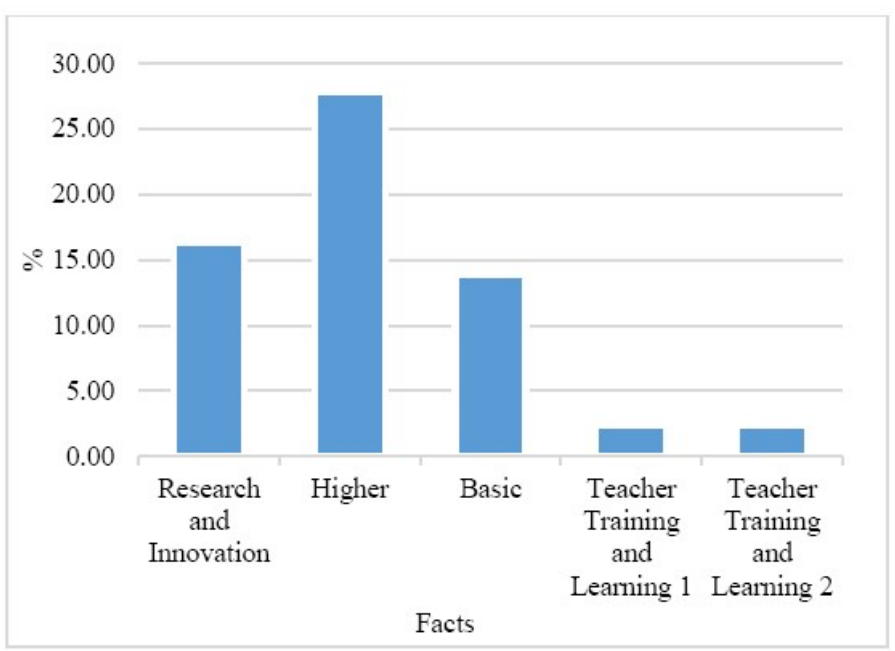

Figure8.3. Comparison of the same facts (little different) of each department for ministry of education

The highest for same facts (little different) is $28 \%$ of the department of higher education and the lowest is $2 \%$ of the department of teacher training and learning 1 and 2 . The deficiency is $24 \%$ and little different. 
The department of research and innovation and basic education is $17 \%$ and $14 \%$. Their deficiency is $3 \%$ and it is not too different.

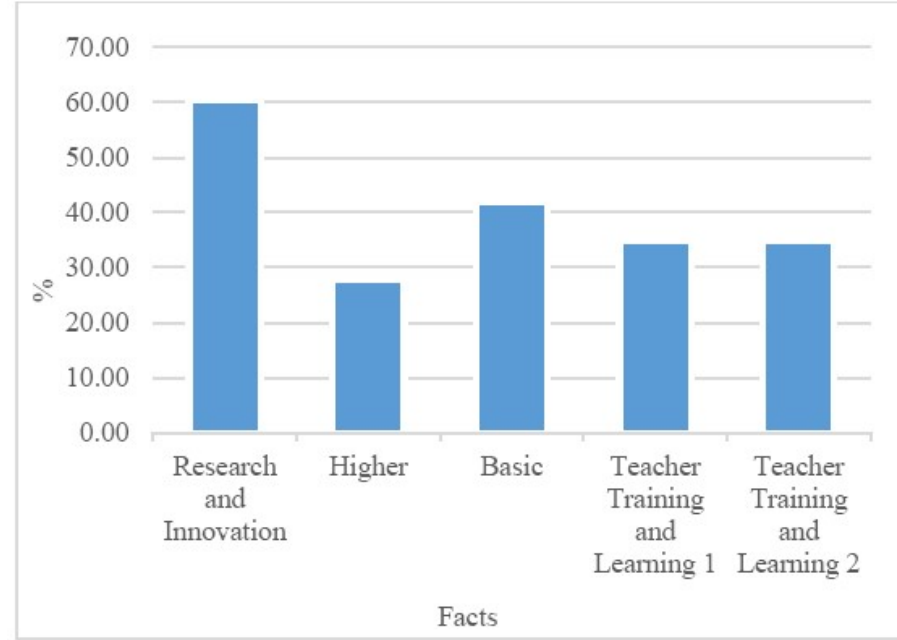

Figure8.4. Comparison of the lack facts (essential) of each department for ministry of education

The department of research and innovation is the highest of $60 \%$ and the higher educaton is the lowest of $28 \%$. The department of higher and basic education are $28 \%$ and $42 \%$. Therefore, their deficiency is $26 \%$ and it is little different in each department.

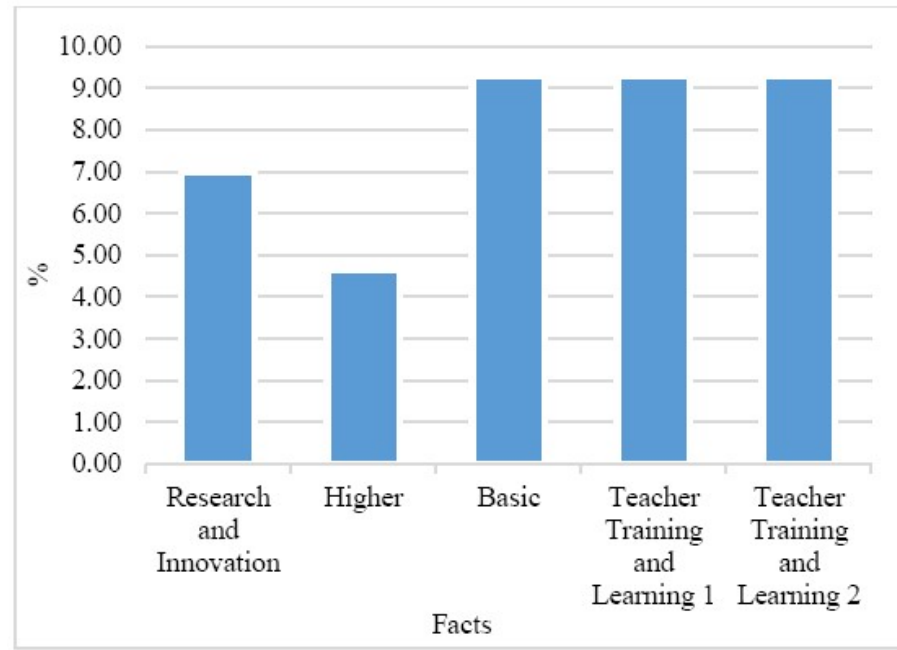

Figure8.5. Comparison of the lack facts (unimportant) of each department for ministry of education

The lack facts that is unimportant to consider is $7 \%$, $5 \%, 9 \%, 9 \%$ and $9 \%$ for department of research and innovation, basic education, higher education, teacher training and learning 1 and 2. The department of research and innovation is $7 \%$. Therefore, the percentages are too low and should removed the kinds of facts.

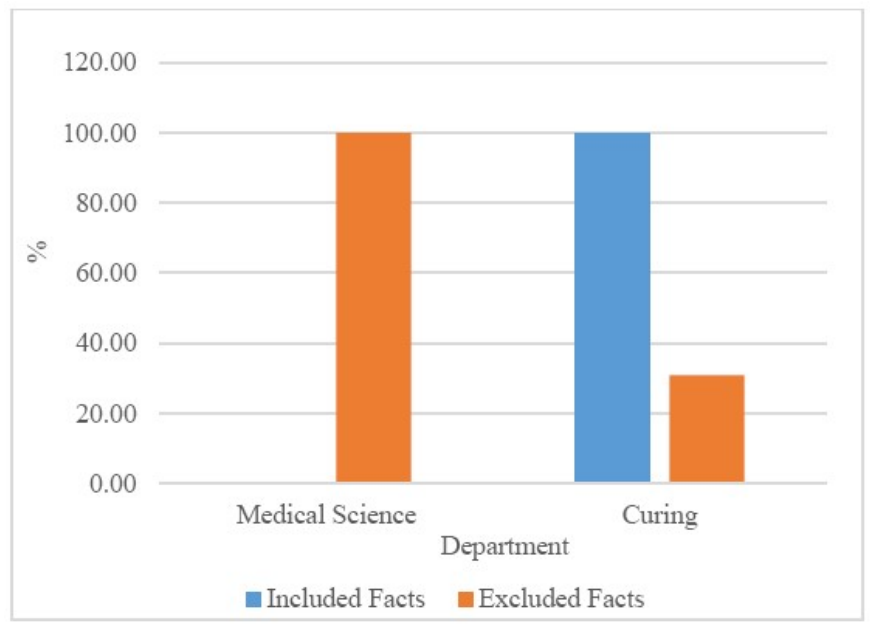

Figure8.6. Comparison of the included and excluded facts of each department for ministry of health

The departments for ministry of health are medical science and curing. There has no same and different facts for this department. The department of general administration is $0 \%$ and the union supreme court is $100 \%$ for the included facts. The deficiency is too higher for both departments. The department of general administration is $100 \%$ and the union supreme court is $31 \%$ for the excluded facts. The same facts (coincide) of the department of medical science is $0 \%$ and that of curing department is $100 \%$. Therefore, the deficiency is $100 \%$ for the first one. Both departments are $0 \%$ for same facts (little different). The lack facts (essential) to include for medical science and curing is $100 \%$ and $0 \%$. The percentage of medical science and curing are $3 \%$ and $0 \%$ for lack facts (unimportant).

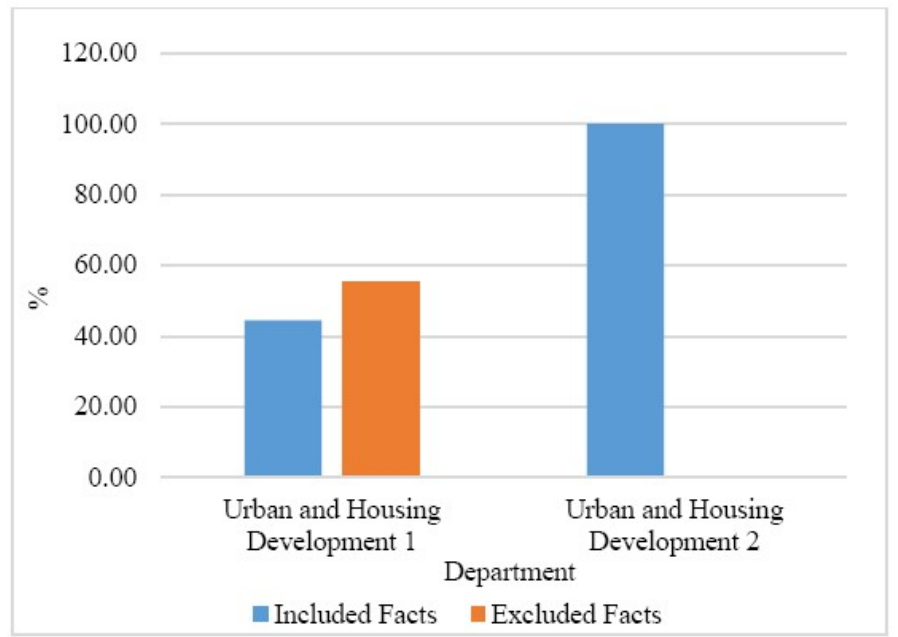

Figure8.7. Comparison of the included and excluded facts of each department for ministry of construction

The department of urban and housing development is included. The same facts are $44 \%$ and the different facts are $56 \%$. The deficiency is $12 \%$. The included facts of comparing the departments of urban and 
housing developmet are $44 \%$ and $100 \%$ and the included facts are $56 \%$ and $0 \%$. The deficiency is $56 \%$ for both included facts and excluded facts.

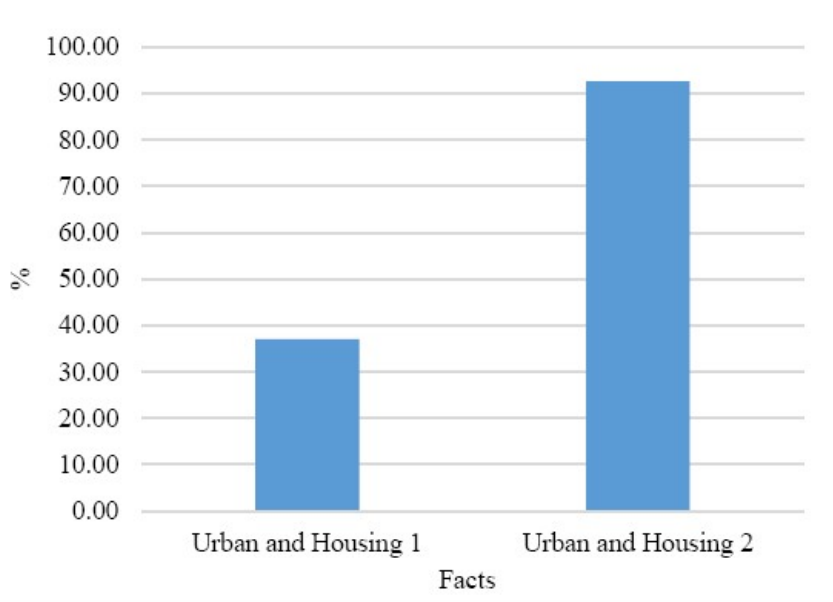

Figure8.8. Comparison of the same facts (coincide) of each department for ministry of construction

The department of urban and houding development for the same facts (coincide) are $93 \%$ and $38 \%$. The deficiency is $55 \%$ and they should nearly same because they are in the same department. The same facts that are little different are similar about $7 \%$ in both departments. The lack facts that are essential to include are $52 \%$ and $0 \%$ in both. The deficiency is $52 \%$ and the percentage is too high. Therefore, the essential facts should be added. The lack facts that are unimportant to include are $3 \%$ and $0 \%$. The deficiency is $3 \%$ and it is not too different.

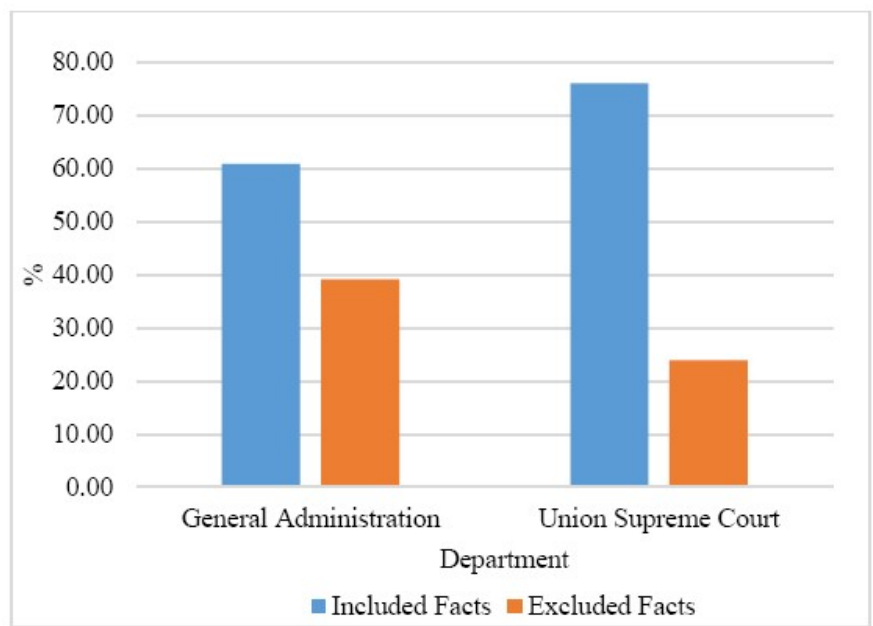

Figure8.9. Comparison of the included and excluded facts of each department for ministry of home affiars

The departments for ministry of home affairs are general administration and union supreme court. The same facts are $37 \%$ and the different facts are $59 \%$. The differency is about $23 \%$. The same facts should be added and the different facts should be adjusted. The included facts are $61 \%$ for general administration and $76 \%$ for union surpreme court. The deficiency is $15 \%$ and it is little different. The excluded facts are $39 \%$ for general administration and $24 \%$ for union supreme court. The deficiency is $14 \%$ and they should be added more facts in each department.

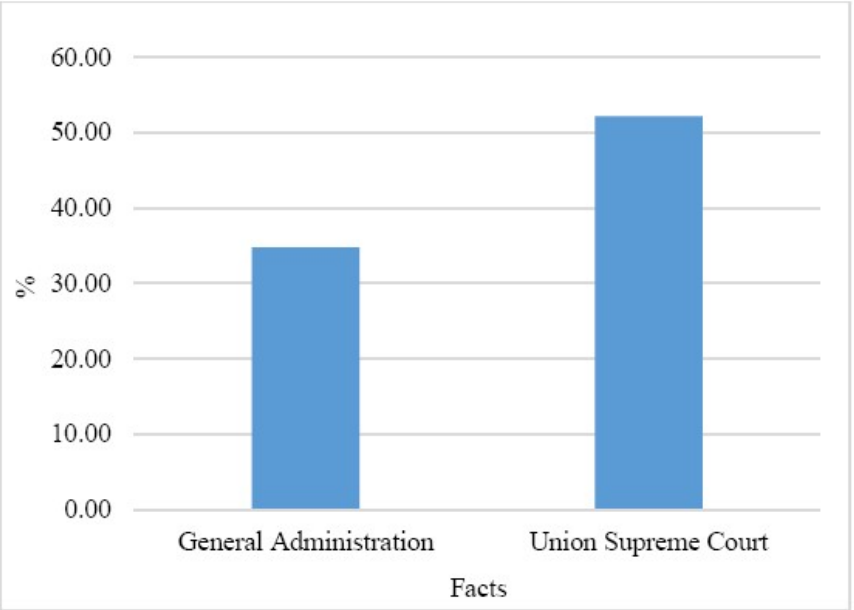

Figure8.10. Comparison of the same facts (coincide) of each department for ministry of home affiars

The same facts (coincide) of general administration are $35 \%$ and that of union supreme court are $52 \%$. The deficiency is $17 \%$ and it is little different. The union Supreme Court is higher than general administration. The department of union supreme court should include the standardized and systematic facts because that department should establish the perfect tender system more than other department. Therefore, both departments should be added more suitable and perfect facts to be same with each department.

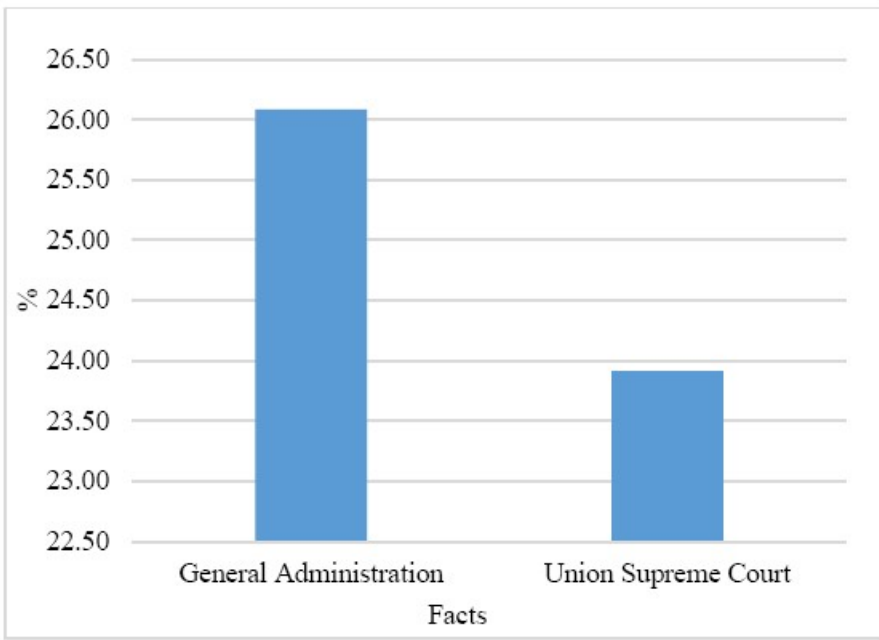

Figure8.11. Comparison of the same facts (little different) of each department for ministry of home affiars 
The same facts that are little different of general administration are $26 \%$ and that of union supreme court are $24 \%$. The deficiency is $2 \%$. The general administration is highet than union supreme court.

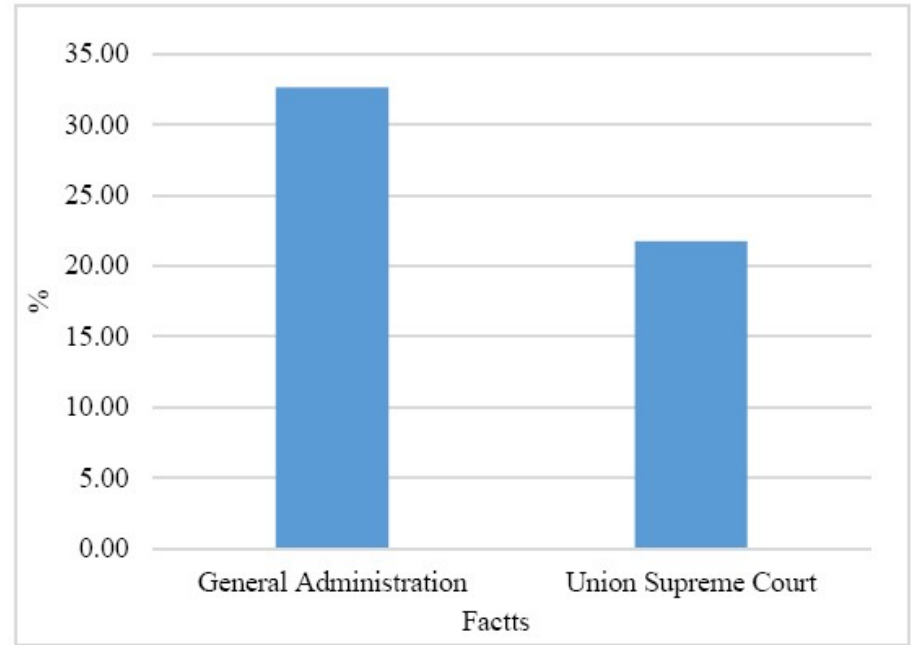

Figure8.12. Comparison of the lack facts (essential) of each department for ministry of home affiars

The lack facts that are essential to include for general administration are $33 \%$ and that of union supreme court are $22 \%$. The deficiency is $11 \%$. The general administration is highet than union supreme court. For lack facts (unimportant), the department of general administration and union Supreme Court is $7 \%$ and $3 \%$. The percentages are too low and some unimportant facts should be removed.

\section{DISCUSSION AND CONCLUSION}

When comparing the same and different facts for each ministry, the same facts are lower than the different facts. The same facts are under $50 \%$ and the higher facts are between 50 and $90 \%$. The same facts should be added and the different facts should be reduced in each ministry. For included facts, ministry of education is 32 to $70 \%$, health is 0 to $100 \%$, construction is 44 to $100 \%$ and home affairs is 60 to $77 \%$. Therefore, ministry of educcation should be added more facts. For excluded facts, ministry of education is 30 to $68 \%$, ministry of health is $0 \%$, ministry of construction is 0 to $56 \%$ and ministry of home affairs is 23 to $40 \%$. Therefore, more facts should be added to the ministry of health, construction and health. The same facts (coincide) of ministry of education are 16 to $54 \%$, that of health are $0 \%$, that of construction are 37 to $93 \%$ and that of home affairs are 34 to $53 \%$. Therefore, ministry of education, health and home affairs should be added more facts. For same facts (little different), ministry of education is 2 to $28 \%$, ministry of of health is 0 to $100 \%$, ministry of of construction is $8 \%$ and ministry of of home affiars is 23 to $27 \%$. The minisrty of health is higher deficiency than other three ministry. The lack facts (essential) of ministry of education is 27 to $61 \%$, health is 0 to $100 \%$, construction is 0 to $52 \%$ and home affairs is 21 to $33 \%$. Therefore, all ministries should be added the essential facts that are lack in each ministry. For lack facts (unimportant), ministry of education is 4 to $10 \%$, ministry of health is 0 to $4 \%$, ministry of construction is 0 to $4 \%$ and ministry of home affairs is 2 to $7 \%$. All ministries should be reduced the unimportant facts. In conclusion, the tender systems of all ministries are unsystematic and have weakness. Therefore, tender systems of all ministres should be added and improved with the needed facts.

\section{ACKNOWLEDGEMENTS}

The author is deeply grateful thanks to his pupil Htet Thinzar Thein for her support and effort to writing this paper.

\section{REFERENCES}

1. Brook. Martin, "Estimating and Tendering for Construction Work", third edition, 2004, Elsevier Ltd.

2. Levy. Sidney. M., "Project Management in Construction", fifth edition, 2007, The McGrawHill Companies, Inc.

3. Dagostino. Frank R., "Estimating in Building Construction", Seventh edition, 2011, Pearson Education, Inc., publishing as Prentice Hall, One Lake Street,Upper Saddle River,New Jersey, 07458 . 